\title{
ARQUEOLOGIA E PODER: A LEGITIMAÇÃO DO ESTADO
}

Archaeology and Power: the state legitimation

\section{Cláudio Umpierre Carlan ${ }^{1}$}

\section{RESUMO}

$\mathrm{O}$ artigo começa por discutir questões políticas relacionadas com o mundo romano nos séculos III e IV d.C. O trabalho enfatiza a importância de usar uma variedade de fontes históricas, como iconográfica, arqueológica e artística.

Palavras-chave: Arqueologia, Moeda, Roma

\begin{abstract}
The paper begins by discussing political issues relating to the Roman world in the $3^{\text {rd }}$. c. AD and in the beginning of the $4^{\text {th }} \mathrm{c}$. The paper emphasizes the importance of using a variety of historical sources, such as iconographic, archaeological, and art historical.
\end{abstract}

Keywords: Archaeology, Coin, Rome

\section{RESUMEN}

El artículo comienza por discutir cuestiones de política relacionadas con el mundo romano en los siglos III y IV d.C. El trabajo hace hincapié en la importancia del uso de una variedad de fuentes históricas, como iconográfica, arqueológica, histórica y artística.

Palabras clave: Arqueología, Moneda, Roma

\section{Introdução}

Em Roma, a propaganda estava intimamente ligada às cunhagens monetárias. As moedas não apenas são instrumentos importantes para estabelecer a datação dos documentos que chegaram até nós sem seu contexto original, como são de grande valia na compreensão dessas mensagens simbólicas descritas no corpo monetário.

O reverso monetário dessas peças, conhecido vulgarmente como coroa, mostra determinada imagem, representando uma divindade (Virtude, Júpiter, Hércules, a própria

\footnotetext{
${ }^{1}$ Pós Doutorando em Arqueologia do NEPAM/UNICAMP, professor adjunto 3 de História Antiga da Universidade Federal de Alfenas (UNIFAL-MG), pesquisador associado ao grupo de pesquisa Arqueologia Histórica da UNICAMP. E-mail: claudiocarlan@yahoo.com.br
} 
cidade de Roma, a VRBS...), uma construção (campo militar, portões de uma fortaleza), o exército (dois legionários montando guarda), cenas de batalha (imperador derrotando seus inimigos), casamentos, uniões dinásticas, tentativa de legitimar um determinado poder. Podendo vir acompanhado de legendas que podem identificar, ou não, a imagem.

Já nos anversos monetários (cara), temos em destaque o busto do imperador diademado (com diadema imperial), laureado (coroa de louros) ou encouraçado (com armadura, couraça, uniformes militares).

A perfeição dos detalhes nos mostra a importância e o cuidado do artesão em confeccionar essas imagens. Pois, num mundo no qual não existiam meios de informação comparáveis aos nossos, o analfabetismo se estendia a numerosas camadas da população, a moeda é um objeto palpável, que abre todas as portas e proporciona bem-estar. Nela, pode-se contemplar o busto do soberano, enquanto os reversos mostram suas virtudes e a prosperidade da época: Felicitas Temporvm, Restitvtio Orbis, Victoria e Pax Avgvsta... são slogans, propaganda (ROLDÁN HERVÁS, 1975: 166).

A moeda, como documento, pode informar sobre os mais variados aspectos de uma sociedade. Tanto político e estatal, como jurídico, militar, religioso, mitológico, estético, artístico.

Nesse texto, daremos um destaque maior a questão política, como os imperadores procuravam legitimar seu governo, através das representações monetárias.

\section{Roma e a legitimação política.}

O desenvolvimento do retrato individual é geralmente considerado como uma das principais realizações da arte romana. Esse ponto de vista é, talvez, um tanto paradoxal, já que os artistas que produziram a maioria dos retratos conservados eram, de fato, gregos. Porém, trabalhavam sob patrocínio de romanos abastados e a sua obra é uma resposta às necessidades romanas e um reflexo dos gostos dessa sociedade.

A característica distintiva desse estilo de retrato é um extremo realismo, com particular realce para os aspectos pouco atraentes dos indivíduos representados. As origens desse estilo verista são difíceis de determinar, mas não há dúvida que agradava muito aos romanos, que gostavam de se ver como um povo forte, honesto e nada fantasioso. Essa característica foi utilizada nas cunhagens monetárias.

Diferente dos gregos, os chamados "inventores" da moeda (segundo Heródoto na Lígia, século VII a. C.), que representavam deuses e personagens ligados à mitologia (dando 
um aspecto sagrado à moeda), os romanos seguiam padrão diferente, adotando uma certa veracidade em seus retratos.

Para conhecermos melhor o mundo romano, Funari afirma que dispomos de diversas fontes de informações como: documentos escritos, objetos, pinturas, esculturas, edifícios, moedas, entre outros (FUNARI, 2002: 78).

Nesse sentido, daremos um destaque maior as amoedações, pois além de oferecer um bem estar econômico, mostra também os seus aspectos icônicos. Analisando os anversos e reversos monetários como imagens fabricadas, elas imitam aquilo a que se referem. Qualquer signo, mesmo o iconográfico gravado segundo processos físicos ou naturais, é construído segundo regras determinadas que implicam convenções sociais. Ela circula de fato nos três níveis, sendo simultaneamente ícone, índice e símbolo convencional.

Os povos que habitavam o vasto império romano tinham conhecimento de que o busto representado naquela diminuta peça de bronze, prata ou ouro era do seu governante.

A moeda foi introduzida em Roma durante a República, na qual, as famílias senatoriais cunhavam suas próprias peças (podemos chamar de uma produção particular). Mas, foi com Augusto (63 a. C. - 14 d. C.) que os aspectos artísticos, não apenas das peças, mas também da arquitetura, são associados a uma propaganda política/ideológica, cuja função era de legitimar o poder do governante (ZANKER, 1992: 86).

No início do século IV, Diocleciano e os demais membros da tetrarquia (295 - 305) realizam uma reforma monetária e uma nova amoedação, os dupondii (CAYON, 1985: 45).

Essa moeda de bronze de diâmetro superior a 2,5mm, pesando mais de $8 \mathrm{~g}$, é identificada, no reverso à representação de Júpiter seminu com os ombros cobertos, nas peças de Diocleciano, ou Hércules com a pele do leão nas de Maximiano, entregando para o imperador o globo, encimado pela Vitória com uma coroa de louros pronto para coroá-lo, como se as divindades protetoras de Roma estivessem abençoando os novos governantes. Fortalecendo assim a legitimação do poder imperial. 

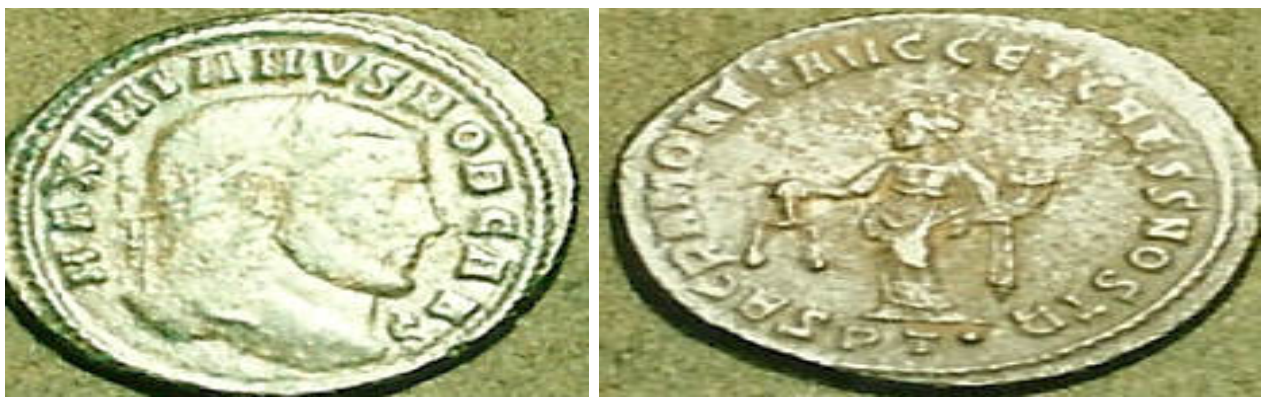

Acervo do Museu Histórico Nacional, Rio de Janeiro. Foto: Cláudio Umpierre Carlan, maio de 2005.

\section{Descrição da Moeda}

\section{Anverso: MAXIMIANVS NOB CAES \\ Reverso: SACRA. MONET. AVGG. ET CAESS. NOSTR}

Busto de Maximiano, à direita, na legenda, descrevemos o título da família imperial romana, usado no século IV, Nobilíssimo César.

No reverso, a deusa Juno, com cornucópia, símbolo da abundância e balança, justiça. Trata-se de uma divindade protetora, comum desde período de Augusto, século I a. C. Como uns dos obetivos da tetrarquia era retorno aos tempos do principado, a partir do governo de Diocleciano, essa mensagem será cada vez mais comum. Os tetrarcas mandaram gravar essa inscrição no mármore do Senado, em Roma.

Outro detalhe significativo foi o banho de prata na peça e o exergo ou linha de terra, PT, que identifica a casa monetária. Nesse caso, primeira casa da moeda de Trier $\mathrm{Ou}$ Tréveres, atual Alemanha. Tanto o exergo, quanto o banho de prata, foram iniciativas de Diocleciano e Maximiano, durante a reforma monetária no início do século IV (CARLAN, 2012: 56).

O banho de prata nas moedas de bronze foi muito utilizado durante a escassez do metal, na Antiguidade Tardia. Apesar de prejudicar a conservação da moeda, por causa da oxidação, alguns exemplares conseguiram manter uma tênue camada de prata, realçando as representações de anverso e reverso.

\section{Numismática e o Estado}

$\mathrm{O}$ artista, nesse caso o artesão, tem a tendência de interpretar o que foi gravado. Com o desenvolvimento do colecionismo do século XVIII, as escavações em Herculano e Pompéia 
(Winckelmann já dizia que a sociedade perfeita, a Clássica, tinha de ser imitada), o gosto pela Antiguidade e o aumento do material disponível nos museus, ajudaram na criação das primeiras sociedades numismáticas do século XIX.

Algo mais que um meio de comunicação, ou de exposição dos grandes mistérios da mitologia, religião, poder. A revolução da imagem como meio de comunicação inicia outros caminhos.

A exposição pública passa ser contemplada em salões e museus. Sendo a moeda um objeto fabricado pela mão do homem, o metal utilizado para fabricação das peças, como também as gravuras e legendas, traz à luz a História Política e das Artes. Já a circulação monetária, auxiliada por um trabalho metodológico de conhecimento das técnicas de análise, é de ajuda fundamental para o estudo da História Econômica.

Nas amoedações mais antigas, seu trabalho chega a ser artesanal. Certas emissões possuem características próprias (como nas moedas cunhadas por Constantino e Constâncio II, por exemplo). Uma mesma série (variantes) pode aparentar diferenças voluntárias ou involuntárias (CORVISIER, 1997: 162), denominadas incidentes das batidas.
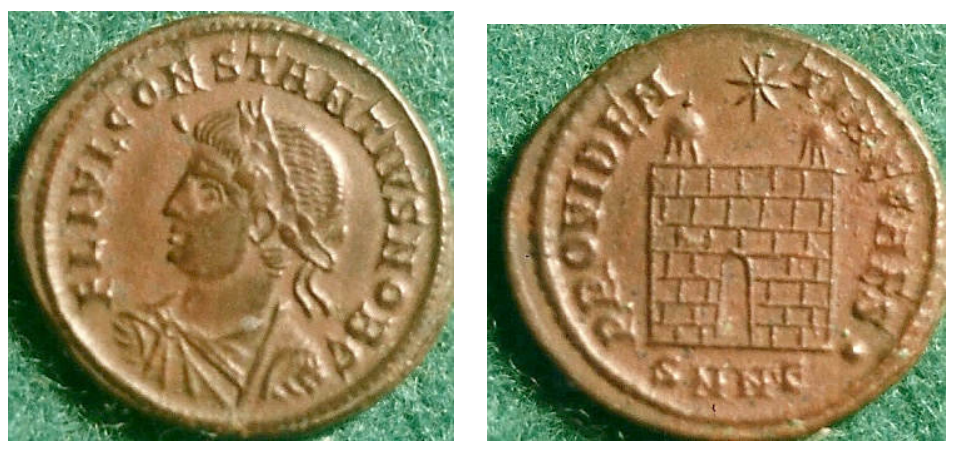

Acervo do Museu Histórico Nacional, Rio de Janeiro. Foto: Cláudio Umpierre Carlan, setembro de 1997.

\section{Descrição da Moeda}

\section{Anverso: FL IVL CONSTANTIVS NOB C \\ Reverso: PROVIDENTIA CAESS / SNN}

No anverso, busto de Constâncio II, filho e herdeiro político de Constantino I, o grande. Na legenda, seu nome (Flavio Júlio Constâncio) e título (Nobilíssimo César), abreviado como era costume em Roma, nos monumentos e amoedações. Face voltada para a esquerda, com diadema, indicando sua ascensão como César. 
Identificamos no reverso, a representação de uma construção, fortaleza ou muralhas de uma cidade, com duas torres, e uma estrela logo acima. No exergo ou linha de terra, o local de cunhagem, segunda casa monetária de Nicomédia.

A estrela remete ao período de Augusto, no qual Suetônio descreve como uma mensagem de Júlio César, reconhecendo sobrinho-neto como seu sucessor e herdeiro.

Segundo Cohen, seria parte de um campo militar aberto (COHEN, 1888: 117). Gomes Marques acrescenta que, tanto as peças de Constâncio II como a de seu pai, Constantino, são as que melhor representam os temas que envolvem as construções (MARQUES, 1982: 137). Nesse sentido, notamos as torres circulares, comum nos portões principais das muralhas a partir do século IV e V.

Denominação, AE3, estado de conservação belo (B), diâmetro de $1.9 \mathrm{~mm}$, peso de $3,70 \mathrm{~g}$, alto reverso 12 horas.

Existem outras peças com representações referentes a esse tema cunhadas na Siscia, Roma, Antioquia, Heracleia, Nicomédia, Cizico (CARLAN, 2012: 72).

Esses incidentes conhecidos porque na época da cunhagem, a peça escapava do controle dos artesãos. Pode-se dizer que a pancada do martelo foi fraca na tentativa de reduplicar a moeda, ou até mesmo o desinteresse dos responsáveis, pois poderiam estar precisando que aquela peça entrasse logo em circulação.

Em Roma, a moeda unificava todo um território que estava submetido a um mesmo poder político.

Mais que a língua e a religião, era um dos poucos instrumentos que permanecia imutável de uma parte a outra do Império. As variações correspondiam às oficinas monetárias e ao chefe do governo. É possível considerá-la como uma transmissora de uma ideologia e do poder político.

Nesse sentido, as amoedações emitiam mensagens do poder de um soberano emissor. Pelo metal precioso, ou não, em que estava lavrada, ela veiculava também a ideologia comum a uma civilização, nesse caso a cristã ocidental ou a orientação política de um governante. As suas legendas, tipos, refletiam a estrutura mental de um povo ou de vários povos, como também retratavam o fato vivido. 


\section{Considerações finais}

Um setor importante das necessidades humanas, satisfeitas mediante as diferentes artes decorativas, corresponde às que se orientam para expressão de uma hierarquia ou a satisfação dos sinais externos do cerimonial prescrito numa determinada circunstância.

Em muitos momentos ao longo da História, essas interiorizações foram consideradas de elementos imprescindíveis para detonar respeito e acatamento para a autoridade constituída, seja de um caráter religioso ou de qualquer outra índole.

Os símbolos que habitam a numismática estão dotados sempre de uma clara organização hieroglífica, pois procedem do fato de que essas imagens difundidas se articulam sempre com o idioma figurado, no qual o poder se expressa secularmente. Trata-se, segundo Flor, do surgimento de representações de águias, leões, como também de torres, cruzes (FLOR: 1995, 183), da fênix, de imperadores ou de personagens pertencentes a uma elite político-econômica, que representam a órbita de ação do poder, chegando ao ponto em que a numismática pode ser definida "como um monumento oficial a serviço do Estado" (FLOR, 1995: 186).

Lembramos ainda que, como afirma Cassirer, “[...] em lugar de definir o homem como um animal rationale, deveríamos defini-lo como um animal symbolicum (CASSIRER, 1977: 70).

O poder não pode ser apreendido pelo estudo do conflito, da luta e da resistência, a não ser em suas manifestações mais restritas. O poder não é característico de uma classe ou de uma elite dominante, nem pode ser atribuído a uma delas.

Para Foucault o poder é uma estratégia atribuída às funções. O poder não se origina nem na política, nem na economia, e não é ali que se encontram suas bases. Ele existe como uma rede infinitamente complexa de micropoderes, de relações de poder que permeiam todos os aspectos sociais. O poder não se reprime, mas também cria. Dentre todos esses aspectos, o mais polêmico de todos é a constatação que o poder cria a verdade e, portanto, a sua própria legitimação. Cabe aos historiadores identificar essa produção da verdade como uma função do poder (HUNT, 1995: 46).

Segundo Funari: “[...] Não se trata, assim, de acreditar no que diz o documento, mas de buscar o que está por trás do que lemos, de perceber quais as intenções e os interesses que explicam a opinião emitida pelo autor, esse nosso foco de atenção" (1993: 86). 


\section{Agradecimentos}

A Pedro Paulo Abreu Funari, José Remesal-Rodríguez, aos colegas e amigos do LAP UNICAMP, pela oportuidade de trocarmos ideias; Maria Beatriz Florenzano, Ciro Flamarion Cardoso, Vera Lúcia Tostes, Eiane Rose Nery, Rejane Maria Lobo Vieira, a Coordenação de Aperfeiçoamento de Pessoal Superior (CAPES). As responsabilidades pelas ideias restringem-se ao autor.

\section{Fontes Numismáticas}

Moedas de Bronze dos seguintes Imperadores: Maximiano e Constâncio II; pertencentes ao acervo do Museu Histórico Nacional/Rio de Janeiro: Medalheiro de Número 3; Lotes Números: 11 ao 37, dando um total de 1888 peças.

\section{Referências bibliográficas}

CARLAN, Cláudio Umpierre. Moeda, Política e Propaganda: as moedas de Constâncio II. Santos: Artefato Cultura, 2012.

CARLAN, Cláudio Umpierre. FUNARI, Pedro Paulo Abreu. Moedas: a numismática e o estudo da História. São Paulo: Annablume, 2012.

CASSIRE, E. Antropologia Filosófica. Ensaio sobre o Homem. São Paulo: Mestre Jou, 1977.

CAYON, Juan. Compendio de las Monedas Del Império Romano. V.2. Madrid: Imprenta Fareso, 1985.

COHEN, Hernry. Description Historique des Monnaies.Frappés Sous L'Empiere Romain. Communément Appelées Médailles Impériales. Deuxième Edition. Tome Septième e Huitième. Paris: Rollim e Feuardent, Éditeurs, 1880-1892.

CORVISIER, Jean-Nicolas. Sources et Methodes em Histoire Ancienne. Pr. Edition. Paris: Presses Universitaires de France, 1997.

DEPEYROT, G. Economie et Numismatique (284-491). Paris: Errance, 1987.

FLOR, Fernando R. de La. Emblemas Lectures de La Imagem Simbólica. Madrid: Alianza Editorial, 1995.

FUNARI, Pedro Paulo Abreu. Grécia e Roma. Vida Pública e vida privada. Cultura, pensamento e mitologia. Amor e sexualidade. $2^{\mathrm{a}}$.ed. São Paulo: Contexto, 2002.

FUNARI, Pedro Paulo Abreu. Roma Vida Pública e Vida Privada. 4.ed. São Paulo: Atual, 1993.

HUNT, Lynn. A Nova História Cultural. São Paulo: Martins Fontes, 1992. 
MARQUES, Mario Gomes. Introdução à Numismática. 1a. ed. Lisboa: Publicações D. Quixote, 1982.

ROLDÁN HERVÁS, J. M. Introducción a la Historia Antigua. Madrid: Ediciones Istmo, 1975.

ZANKER, Paul. Augusto y el Poder de las Imágenes. Madrid: Alianza Editorial, 1992. 